\title{
Conventional voltage electrophoresis for formiminoglutamic-acid determination in folic acid deficiency
}

\author{
J. KOHN, D. L. MOLLIN, AND L. M. ROSENBACH \\ From Queen Mary's Hospital, Roehampton, and the Department of Haematology, \\ Postgraduate Medical School of London
}

SYNOPSIS A new method for the determination of urinary formiminoglutamic acid (FIGLU) using conventional electrophoresis at 200 to $500 \mathrm{v}$. on cellulose acetate strips is reported. Experience in 166 determinations on 137 patients shows the method to be a simple, practical, and apparently sensitive one for the determination of FIGLU in the urine.

Results of the application of the measurement of urinary FIGLU with histidine loading as a test for folic acid deficiency are also reported.

In 1951, Bakerman, Silverman, and Daft detected a precursor of glutamic acid in the urine of folic aciddeficient rats. This material was found to be formiminoglutamic acid (FIGLU) and was shown to be an intermediate product of histidine metabolism (Borek and Waelsch, 1953; Tabor, Silverman, Mehler, Daft, and Bauer, 1953; Tabor and Mehler, 1954; Seegmiller, Silverman, Tabor, and Mehler, 1954). It was also found that for the further metabolism of FIGLU to glutamic acid, folic acid in the form of tetrahydrofolic acid is required (Miller and Waelsch, 1956 and 1957; Tabor and Rabinowitz, 1956). The metabolism of histidine and the relationship to folic acid is as follows:
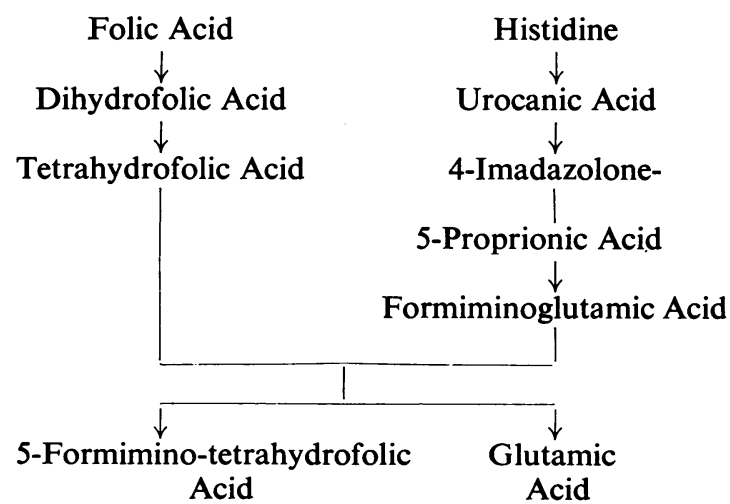

Therefore in the presence of folic acid deficiency FIGLU is not further metabolized to glutamic acid

Received for publication 1 April 1961. and appears in increased amounts in the urine. Increased urinary FIGLU has been demonstrated in patients with amethopterin-treated leukaemia (Broquist, 1956; Hiatt, Goldstein, and Tabor, 1958; Broquist and Luhby, 1959) and in megaloblastic anaemias due to folic acid deficiency (Broquist and Luhby, 1959; Luhby, Cooperman, and Teller, 1959a and 1959b; Spray and Witts, 1959). The use of histidine loading increases the sensitivity of the test (Luhby, et al., 1959b).

Although the measurement of urinary FIGLU was considered to be a sensitive test for folic acid deficiency, clinical application has been limited by the complexities of the methods required for the determination of FIGLU. These methods include a microbiological assay using Lactobacillus arabinosus (Silverman, Gardiner, and Bakerman, 1952; Broquist, 1956), an enzymatic method (Tabor and Wyngarden, 1958), and a combined enzymatic-microbiological technique (Silverman, Gardiner, and Condit, 1958). Paper chromatography (Silverman et al., 1952) has also been used, but was not regarded to be sufficiently sensitive. Knowles, Prankerd, and Westall (1960) introduced the use of high-voltage electrophoresis for FIGLU determination but this method requires expensive equipment and the use of 2,000-6,000 volts.

Recently we introduced the use of conventional voltage electrophoresis on cellulose acetate strips as a simple and practical method for the determination of FIGLU (Kohn, Mollin, and Rosenbach, 1961). We now wish to report the method in detail and its application as a test for folic acid deficiency. 


\section{METHOD}

PRINCIPLE Formiminoglutamic acid (FIGLU) in the urine is separated by means of small-scale cellulose acetate electrophoresis (Kohn, 1959, 1960) in a pyridine-acetic acid buffer. It is then demonstrated by staining with ninhydrin after exposure to ammonia, which converts FIGLU to glutamic acid. Two parallel aliquots of the patient's urine (after administration of histidine) are run at the same time and under the same conditions, together with aliquots of a 'marker' urine containing a known quantity of FIGLU. By comparing the corresponding spots on the ammoniated strip with those on the nonammoniated one the presence of FIGLU in the urine can be detected and its approximate concentration estimated. With a current of $200 \mathrm{v}$. the mobilities of FIGLU and glutamic acid are almost identical and their spots overlap to a great extent. The interpretation of the results is, however, quite easy due to the fact that FIGLU can only be demonstrated on the ammoniated strip.

Using higher voltages, 400-500 v., a satisfactory separation of FIGLU from glutamic acid can be achieved without overlapping. The choice of the method depends mainly on the degree of experience and whether a suitable power pack is available. For routine purposes, however, $200 \mathrm{v}$. is recommended as being simpler and more reliable.

\section{MATERIALS}

SUPPORTING MEDIUM Cellulose acetate strips (Oxo Ltd.) are supplied in $36 \times 5 \mathrm{~cm}$. size. For the FIGLU technique use $12 \times 5 \mathrm{~cm}$. strips.

BUfFer solution Pyridine-acetic acid buffer $p \mathrm{H} 5.3$ is made up of pyridine, $50 \mathrm{ml}$., glacial acetic acid, $20 \mathrm{ml}$., distilled water, 4 litres.

LOCATION REAGENT This is a ninhydrin solution in ethanol ether. Dissolve $0.2 \mathrm{~g}$. ninhydrin in $6 \mathrm{ml}$. of ethanol and make up to $100 \mathrm{ml}$. with diethyl ether. This ninhydrin reagent appears to be particularly suitable for cellulose acetate separation. It is recommended that traces of ammonia be removed from the ninhydrin reagent; this can be done by adding a cation-exchange resin in hydrogen form (Jacobs, 1960).

AMMONIA $\mathbf{0 . 8 8}$.

FIGLU MARKER This can be prepared by adding a known amount of FIGLU to acidified normal urine. The final concentration of FIGLU in this marker urine can be made into a series covering a range from 100 to $1,000 \mu \mathrm{g}$. per $\mathrm{ml}$. Pure FIGLU, however, is difficult to prepare and it is not yet commercially available. It is much simpler to use as a marker a FIGLU-positive urine from a patient with folic acid deficiency. If the FIGLU concentration of such marker is once estimated it can be used for approximate quantitative determinations. The FIGLU concentration of acidified urine, to which a few thymol crystals are added, does not change for many months if kept at $4^{\circ} \mathrm{C}$. glass CAPILlaRY AUtOMATIC PIPETTES These are most 음 useful, and can be easily prepared in the laboratory $\vec{F}$ (Dacie, 1956). They should deliver 6.5 to $7 \mu \mathrm{l}$. It is recom- $\mathscr{O}$ mended to make the capillary part from thick-walled glass so as to obtain a fair length. The pipettes are washed out with the buffer between applications.

\section{APPARATUS}

A horizontal tank suitable for cellulose acetate electrophoresis is required. All our separations were performed $\vec{O}$ on a Shandon universal (Kohn) tank. The bridge gap, i.e., the distance between the shoulder pieces, is set at $\vec{w}$ $10 \mathrm{~cm}$. With a $12 \times 5 \mathrm{~cm}$. strip an overlap of $1 \mathrm{~cm}$. is thus obtained.

\section{CURRENT}

Current is supplied by a constant voltage power pack $\stackrel{t}{\mathrm{c}}$ capable of delivering $200 \mathrm{v}$. With the buffer recom-0 mended a current of $2-2.5$ m.amp. per strip would be obtained. Due to heat generation the current tends to rise during the run.

HISTIDINE ADMINISTRATION AND COLLECTION OF URINE SAMPLE

L-Histidine monohydrochloride, $15 \mathrm{~g}$., is given by mouth to the patient in a fasting state and food is withheld until one hour after the administration of the dose. As the $\bar{\partial}$ histidine is only slightly soluble it is administered by mixing it with water in a glass and then the residue in the $\mathbb{D}$ glass is washed down with water until all the histidine has been taken.

Three hours after taking the dose the patient voids urine and this is discarded. All urine passed over the next five hours (three to eight hours after histidine) is collected in a bottle to which has been added $1 \mathrm{ml}$. of concentrated hydrochloric acid and a few thymol crystals. The urine? volume is measured and an aliquot taken for analysis. The $\frac{\sigma}{3}$ collection period of between three and eight hours is used as the determination of hourly FIGLU excretion in $\delta$ patients has shown the peak excretion of FIGLU to occur during this time.

\section{TECHNIQUE OF ASSAY}

The technical electrophoretic details are essentially the $\bar{N}$ same as recommended for cellulose acetate electrophoreis in general (Kohn, 1959, 1960).

1 Mark the cellulose acetate strips with a soft $N$ pencil or preferably with non-diffusable ink with the $\sigma$ name of patient, date, and with dots indicating the application sites in the following pattern:

Figlu marker

Patient's urine

Figlu marker

This pattern is arbitrary, of course, and any other arrangement meeting some particular requirements can be $\delta$ adopted. 
2 Impregnate the strip with the buffer solution. It is essential to float the strip first and to submerge only after it has soaked up from underneath.

3 After impregnation, blot the strip lightly on both sides between two sheets of filter paper. No excess moisture should be seen.

4 Place the strip in position in the apparatus.

5 Apply 6.5 to $7 \mu 1$. samples of patient's urine to the two previously marked centre spots and the FIGLU marker urine on the lateral spots. This is best performed by means of a glass capillary automatic pipette.

6 Close the lid and apply a constant voltage of $200 \mathrm{v}$. for 30 minutes. The timing may vary somewhat, depending upon conditions. The optimal time will soon be found by experience.

7 After the run is completed, remove the strips and dry them in an oven at 80 to $100^{\circ} \mathrm{C}$. for 10 to 15 minutes until they are completely dry. An oven with a fan would be preferable.

8 Cut the strip into two identical halves lengthwise. Each cut part will now be a mirror image of the other.

9 Place one half strip into a container with ammonia (strip hung from the lid and a beaker with ammonia in the bottom of the container) for about 30 minutes.

10 After removing the strip from the ammonia atmosphere, dry it again at 90 to $100^{\circ} \mathrm{C}$. for a few minutes, in order to drive off the ammonia.

11 STAINING Place the ninhydrin solution in a small evaporating basin or Petri dish and pass the strip slowly through the solution. It will start drying almost immediately and, at this stage, tends to curl slightly. Place it, therefore, flat between two sheets of filter paper lying between two pieces of cardboard; clip the cardboard pieces together with two Bulldog clips and put it back into the oven at 90 to $100^{\circ} \mathrm{C}$. for about five minutes. The strips can then be inspected, but the colour does not develop fully until about 30 minutes. Inspect the strip by transmitted light using a bright lamp.

12 evaluation It has to be remembered that the whole procedure is essentially based on the comparison between the ammoniated and the non-ammoniated strips. The patterns obtained are shown in Figs. 1 and 2. Three spots can be seen on each strip; the spot nearest the cathode corresponds mainly to histidine, the one near the application line in the centre contains glycine, and the spot towards the anode is glutamic acid, which in most urines is usually very faint. If FIGLU is present in the urine it can be detected only on the ammonia-exposed strip as a spot corresponding to the mobility of the FIGLU marker and merging with the glutamic acid spot. A semi-quantitative estimation of the amount of FIGLU present can be obtained by comparing the intensity of the colour of the marker spot with the patient's FIGLU spot. If the FIGLU spot is very intense the patient's urine should be diluted in such a manner that the resulting colour intensity will be close to that of the marker urine. The dilutions should be made with acidified urine (preferably the patient's own urine before histidine was given or with any normal urine). Diluting with water is not re3

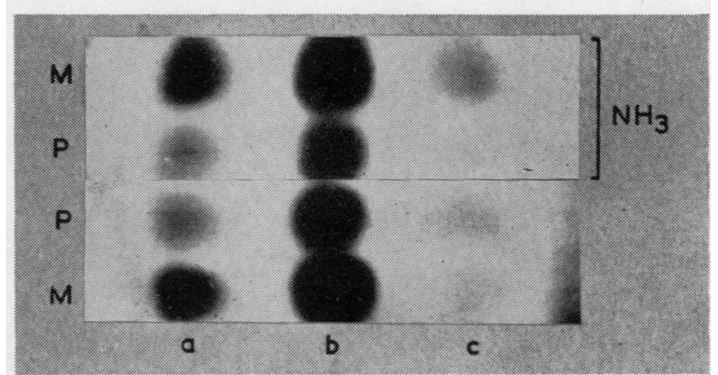

FIG. 1. Electrophoretic pattern of a FIGLU-negative urine.

$M=$ marker urine containing $100 \mu g . F I G L U / m l . P=$ patient's urine.

$a$, histidine, $b$, glycine, $c$, glutamic acid (very faint) and FIGLU (in marker urine on ammoniated strip) $200 v$, 30 min. run, contact print.

Note traces of glutamic acid on non-ammoniated strip.

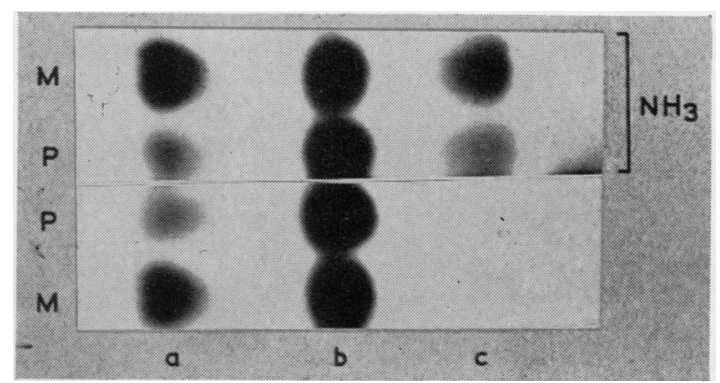

FIG. 2. Electrophoretic pattern of a FIGLU-positive urine. $M=$ marker urine containing $200 \mu \mathrm{g}$. of FIGLU/ml. $P=$ patient's urine.

$a$, histidine, $b$, glycine, $c$, glutamic acid and FIGLU. 200 v., 30 min. run, contact print.

Practically no glutamic acid present.

commended. An approximate estimation can also be performed by interpolation between two known standards.

With careful technique and some experience the presence of as little as $20 \mu \mathrm{g}$. of FIGLU per ml. of urine can be detected. Pure FIGLU can be detected in even smaller concentrations.

The amount of FIGLU in the urine is then expressed in milligrams per hour over the five-hour collection period (between the third and the eighth hour after the administration of $15 \mathrm{~g}$. histidine).

\section{SEPARATION AT $400 \mathrm{~V}$.}

This is an alternative procedure which permits a clear separation of the FIGLU and the glutamic acid spots (Fig. 3). The separation can be achieved by the application of a higher voltage, i.e., 400 up to $500 \mathrm{v}$. The time of running is 20 minutes. Under these conditions the basic amino-acids (histidine group) run off the strip into the cathode buffer. The sample should be applied as an 


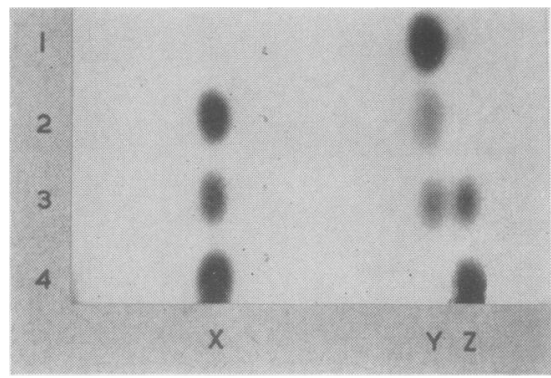

FIG. 3. Electrophoretic pattern of a FIGLUpositive urine together with artificial mixtures of amino-acids and FIGLU showing clear separation of FIGLU from glutamic acid. 1, FIGLU; 2, FIGLU-positive urine (only trace of glutamic acid present); 3, mixture of histidine, glycine, and glutamic acid, and FIGLU; 4, mixture of histidine, glycine, and glutamic acid but without FIGLU.

$X$, glycine, $Y, F I G L U, Z$, glutamic acid. Note absence of histidine spot which has been allowed to run off the strip into buffer. Contact print.

elliptical drop, moving the tip of the pipette slightly at right angles to the direction of the run. The current should not exceed 4-5 m.amp. if overheating is to be avoided. A rapid fall in the amperage indicates overheating and in this case semi-transparent areas can be observed. In all other respects the technique is exactly the same as with $200 \mathrm{v}$.

It should be pointed out, however, that the conditions of this method are somewhat more critical. The technique requires more experience and a power pack capable of delivering up to $500 \mathrm{v}$. The danger of overheating the strip is greater, particularly with a higher ambient temperature. Sometimes a syphoning effect, probably due to the excessive evaporation in the centre of the strip, may cause small areas or bands of discoloration after ninhydrin staining. With some experience, however, there is no difficulty in the interpretation of the results.

\section{INVESTIGATIONS AND DIAGNOSTIC CRITERIA}

All of the FIGLU determinations were carried out by one of us to whom the urine samples were sent without any clinical information on the patients. Therefore, any possible element of bias in the determination was eliminated.

Each of the patients tested had a complete blood count, and a serum vitamin $B_{12}$ level was measured by microbiological assay with Euglena gracilis (Hutner, Bach, and Ross, 1956) and a serum folic acid level with the modified $L$. case $i$ method (Waters and Mollin, 1961). A bone marrow biopsy was performed on all of the anaemic patients, and when indicated vitamin $B_{12}$ and folic acid absorption studies were done. In most of the patients with a megalo- $-\underline{\underline{\sigma}}$ blastic anaemia, the haematological response to $0.4 \mathrm{mg}$. folic acid or $2 \mu \mathrm{g}$. vitamin $\mathrm{B}_{12}$ a day was? followed.

Patients diagnosed as idiopathic steatorrhoea had evidence of malabsorption with a typically abnormaf? jejunal biopsy. Patients were considered to have å nutritional folic acid deficiency if there was a megalo-e blastic anaemia with a normal serum $\mathrm{B}_{12}$ level, a poordietary history, a normal jejunal biopsy, no evidence of malabsorption of $B_{12}$ or folic acid, and if they had not been taking anticonvulsant drugs. Pernicious? anaemia was diagnosed by the usual criteria and? confirmed with radioactive $B_{12}$ absorption tests. $\vec{A}$ Patients designated as having a post-gastrectomy megaloblastic anaemia due to $B_{12}$ deficiency had $a_{f}^{\omega}$ partial or total gastrectomy, a megaloblastic bone ${ }^{\mathrm{r}}$ marrow, a low serum $B_{12}$ level, and radioactive $B_{12} ?$ absorption studies similar to those of pernicious anaemia.

\section{RESULTS}

One hundred and sixty-six tests have now been carried out on 137 patients with various disease states. In Table $I$ are summarized the results on the normal controls and patients with idiopathic steatorrhoea, nutritional folic acid deficiency, $\stackrel{\circ}{\mathscr{Q}}$ vitamin $\mathrm{B}_{12}$ deficiency, iron deficiency, and a few $\overrightarrow{\vec{P}}$ miscellaneous conditions.

Most normals showed no detectable FIGLU in? the urine by this test. In an occasional normal subjecto a trace of FIGLU may be present but the calculated excretion has never been greater than $2 \mathrm{mg}$./hour.

In all patients with clinical evidence of folic acido deficiency the excretion has been greater than: $3.5 \mathrm{mg}$./hour.

The highest levels of FIGLU with a range of 30 to $80 \mathrm{mg}$./hour were most consistently obtained in the untreated cases of idiopathic steatorrhoea, all of which showed haematological evidence of folic acid deficiency. Three patients who were well controlled N on gluten-free diets for periods of one to two years showed a lower but still elevated urinary FIGLU excretion with a range of 4 to $8 \mathrm{mg}$./hour.

Several patients with idiopathic steatorrhoea were treated with intramuscular injections of $0.4 \mathrm{mg}$. of folic acid a day, and in spite of an excellent haematological response serial FIGLU determinations ${ }^{-}$ showed only a gradual return towards normal. In one patient, for example, the FIGLU excretion after $30 \frac{\mathrm{D}}{\mathrm{D}}$ days of treatment with $0.4 \mathrm{mg}$. of folic acid a day had? decreased from $44 \mathrm{mg}$./hour to $15 \mathrm{mg}$./hour. A largę dose of folic acid, $10 \mathrm{mg}$. per day, was then instituted,, and the FIGLU excretion became normal within another seven days. 
TABLE I

URINARY FIGLU EXCRETION IN NORMAL CONTROLS AND VARIOUS DISEASE STATES

\begin{tabular}{|c|c|c|c|c|c|c|}
\hline Diagnosis & Total & $\begin{array}{l}\text { Positive } \\
\text { FIGLU }\end{array}$ & $\begin{array}{l}\text { Negative } \\
\text { FIGLU }\end{array}$ & $\begin{array}{l}\text { FIGLU (mg./hr.) } \\
\text { (normal } \\
2 m g . / h r .)\end{array}$ & $\begin{array}{l}\text { Serum } \\
\text { Folic Acid } \\
(\mu g . / m l .) \\
(\text { normal } \\
>5 \mu g . / m l .)\end{array}$ & $\begin{array}{l}\text { Serum } \\
\text { Vitamin } \mathrm{B}_{12} \\
(\mu \mu \mathrm{g} . / \mathrm{ml} .) \\
(\text { normal } 140-900 \\
\mu \mu \mathrm{g} . / \mathrm{ml} .)\end{array}$ \\
\hline Normal controls & 14 & 0 & 14 & $<2$ mg./hr. & $5-18$ & $230-790$ \\
\hline $\begin{array}{l}\text { Idiopathic steatorrhea } \\
\text { (a) Untreated } \\
\text { (b) Gluten-free diet } \\
\text { Nutritional folic acid deficiency }\end{array}$ & $\begin{array}{r}12 \\
9 \\
3 \\
6\end{array}$ & $\begin{array}{r}12 \\
9 \\
3 \\
6\end{array}$ & $\begin{array}{l}0 \\
0 \\
0 \\
0\end{array}$ & $\begin{array}{l}30-80 \\
4-8 \\
4-20\end{array}$ & $\begin{array}{l}1 \cdot 2-3 \cdot 5 \\
2 \cdot 8-5 \\
<1-3 \cdot 5\end{array}$ & $\begin{array}{l}190-275 \\
190-530 \\
165-390\end{array}$ \\
\hline $\begin{array}{l}\text { Pernicious anaemia } \\
\text { Post-gastrectomy məgaloblastic an zemia } \\
\text { Terminal ileum resection }\end{array}$ & $\begin{array}{l}7 \\
6 \\
1\end{array}$ & $\begin{array}{l}3 \\
1 \\
0\end{array}$ & $\begin{array}{l}4 \\
5 \\
1\end{array}$ & $\begin{array}{l}11-48 \\
\quad 6 \\
<2 \mathrm{mg} . / \mathrm{hr}\end{array}$ & $\begin{array}{l}10-23 \\
5-20 \\
17\end{array}$ & $\begin{array}{l}35-80 \\
45-120 \\
30\end{array}$ \\
\hline Iron-deficiency anaemia & 8 & 0 & 8 & $<2 \mathrm{~m} \cdot \mathrm{g} / \mathrm{hr}$ & $7 \cdot 4-20$ & $240-625$ \\
\hline $\begin{array}{l}\text { Acute leukaemia on amethopterin therapy } \\
\text { Megaloblastic anaemia associated with anticonvulsant } \\
\text { therapy } \\
\text { Megaloblastic anaemia associated with clinical scurvy }\end{array}$ & $\begin{array}{l}3 \\
1 \\
1\end{array}$ & $\begin{array}{l}3 \\
1 \\
1\end{array}$ & $\begin{array}{l}0 \\
0\end{array}$ & $\begin{array}{l}24-55 \\
16 \\
12\end{array}$ & $\begin{array}{l}0-6 \\
1 \cdot 7\end{array}$ & $\begin{array}{l}570 \\
165 \\
250\end{array}$ \\
\hline
\end{tabular}

The six cases of nutritional folic acid deficiency also had elevated urinary FIGLU levels but of lower magnitude, ranging from 4 to $20 \mathrm{mg}$./hour. In all of these patients with idiopathic steatorrhoea and nutritional folic acid deficiency the serum folic acid level was low.

Of the 14 cases of vitamin $B_{12}$ deficiency (seven with pernicious anaemia, six with post-gastrectomy megaloblastic anaemia, one with a terminal ileum resection), 10 showed no increase in urinary FIGLU. However, four patients, three with pernicious anaemia and serum $B_{12}$ levels between 40 and 65 $\mu \mu \mathrm{g} . / \mathrm{ml}$. and the other with a post-gastrectomy megaloblastic anaemia and a serum $B_{12}$ level of $45 \mu \mu \mathrm{g} . / \mathrm{ml}$., had increased FIGLU in the urine. In all 14 of these cases with vitamin $B_{12}$ deficiency the serum folic acid level was normal. One of the patients with untreated pernicious anaemia was given $0.4 \mathrm{mg}$. of folic acid daily for 14 days without a significant haematological response.

The urinary FIGLU was not increased in eight patients with uncomplicated iron-deficiency anaemia.

In addition, increased urinary FIGLU was detected in three patients with acute leukaemia on amethopterin therapy, one case of megaloblastic anaemia related to anticonvulsant therapy, and in one patient with a megaloblastic anaemia in association with clinical scurvy. Increased FIGLU in the urine has also been present in a number of cases of widely disseminated carcinoma, haemolytic anaemia, and active liver disease. Six of seven patients with sarcoidosis also showed raised urinary FIGLU levels.

These results will be reported and discussed in greater detail elsewhere. 
is uncertain but it may possibly represent concomitant or secondary folic acid deficiency (Chanarin, Mollin, and Anderson, 1958). Nevertheless, the serum folic acid level was normal in all four of these cases as well as in the other 10 cases of vitamin $B_{12}$ deficiency (Table I). In all four cases the excessive excretion of FIGLU disappeared when the patients were treated with vitamin $B_{12}$. It is therefore possible that the excessive excretion of FIGLU by these patients was due to a defect in folic acid metabolism caused by the deficiency of vitamin $B_{12}$.

A number of patients with disseminated carcinoma, active liver disease, and sarcoidosis, many of whom showed no megaloblastic change in the marrow, had an elevated urinary excretion of FIGLU. Whether this represents tissue depletion of folic acid or whether it is due to deficiency of FIGLU transferase or folic acid-reducing enzymes, as suggested in alcoholic cirrhosis of the liver (Carter, Schaffner, and Heller, 1960), is not known. In this connexion the persistence of the increased FIGLU excretion in patients with folic acid deficiency while on treatment with $0.4 \mathrm{mg}$. of folic acid daily, in spite of an excellent haematological response, suggests that the test may be very sensitive to depletion of folic acid in the tissues. However, until more is known about the specificity and sensitivity of FIGLU excretion, the meaning of these findings is uncertain.

We wish to thank Dr. Lester Smith, F.R.S., of the Research Division of Glaxo Laboratories, Ltd., and Dr. Herbert Tabor, of the National Institutes of Health, for supplying samples of purified formiminoglutamic acid; Dr. C. C. Booth and the other physicians of the Hammersmith Hospital, the physicians of Queen Mary's Hospital, Roehampton, Dr. K. Dormandy, of the Hospital for Sick Children, Great Ormond Street, Dr. N. Richardson, of Epsom District Hospital, and Dr. N. F. Coghill and Dr. J. S. Selwyn, of West Middlesex Hospital, for permission to study patients under their care.

We also thank Mrs. Shirley Lichtigfeld, Miss Rachel Smith, Miss Josephine Pope, and Miss Thurl Towler for carrying out the microbiological assays.

\section{REFERENCES}

Bakerman, H. A., Silverman, M., and Daft, F. S. (1951). J. biol. $\overline{\bar{C}}$ Chem., 188, 117.

Borek, B. A., and Waelsch, H. (1953). Ibid., 205, 459.

Broquist, H. P. (1956). J. Amer. chem. Soc., 78, 6205. , and Luhby, A. L. (1959). Proc. Soc. exp. Biol. (N.Y.), 100,

Carter, F. C., Schaffiner, G., and Heller, P. (1960). Clin. Res., 8., $\stackrel{\text { \& }}{349 .}$ 199.

Chanarin, I., Mollin, D. L., and Anderson, B. B. (1958). Brit. J. Haemat., 4, 435.

Dacie, J. V. (1956). Practical Haematology, 2nd ed., p. 221. Churchill, London.

Herbert, V., Baker, H., Frank, O., Pasher, I., Sobotka, H., and $\underset{\omega}{\omega}$ Wasserman, L. R. Unpublished data as cited in Herbert, V., Baker, H., Frank, O., Pasher, I., Sobotka, H., and Wasserman, ত L. R. (1960). Blood, 15, 228.

Hiatt, H. H., Goldstein, M., and Tabor, H. (1958). J. clin. Invest., 37, 829.

Hutner, S. H., Bach, M. K., and Ross, G. I. M. (1956). J. Protozool., 3, 101.

Jacobs, S. (1960). Analyst, 85, 257.

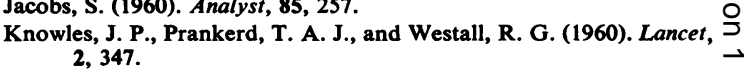

Kohn, J. (1959). In Protides of the Biological Fluids: Proceedings of the 6th Colloquium, Bruges, 1958, ed. H. Peeters, p. 74. Elsevier Publishing Co., Amsterdam.

-, (1960). Chromatographic and Electrophoretic Techniques, ed. Ivor Smith, Vol. 2, p. 56. Heinemann, London.

_, Mollin, D. L., and Rosenbach, L. M. (1961). Lancet, 1, 112.

Luhby, A. L., Cooperman, J. M., and Teller, D. N. (1959a). Amer, J. clin. Nutr., 7, 397.

$\longrightarrow$, (1959b). Proc. Soc. exp. Biol. (N. Y.), 101, 350.

Marshall, R. A., Jandl, J. H., Castle, W. B., and Hiatt, H. H. Personal communication as cited in Herbert, V., Baker, H., Frank, O., @ Pasher, I., Sobotka, H., and Wasserman, L. R. (1960). Blood, 응 $15,228$.

Miller, A. and Waelsch, H. (1956). Arch. Biochem. Biophys., 63 263.

Rucknagel, D., La Du, B. N., Laster, L., Seegmiller, J. E., Daft, F. S., Silverman, M., and Pitney, A. J. Personal communication as cited in Herbert, V., Baker, H., Frank, O., Pasher, I., Sobotka. H., and Wasserman, L. R. (1960). Blood, 15, 228.

Seegmiller, J. E., Silverman,|M., Tabor,jH.,fand Mehler,:A. H. (1954) J. Amer. chem. Soc., 76, 6205.

Silverman, M., Gardiner, R. C., and Bakerman, H. A. (1952). J. biol. Chem., 194, 815.

- and Condit, P. T. (1958). J. nat. Cancer Inst., 20, 71

Spray, G. H., and Witts, L. J. (1959). Lancet, 2, 702.

Tabor, H., and Mehler, A. H. (1954). J. biol. Chem., 210, 559. Silverman, M., Mehler, A. H., Daft, F. S., and Bauer, H. (1953). J. Amer. chem. Soc., 75, 756. , and Rabinowitz, J. C. (1956). ibid., 78, 5705.

, and Wyngarden, L. (1958). J. clin. Invest., 37, 824.

Waters, A. H., and Mollin, D. L. (1961). J. clin. Path., 14, 335. 